\title{
The Relationship between Glomerular Filtration Rate and Mean Platelet Volume in Chronic Kidney Disease Patients without Dialysis
}

\author{
Zeynep Ata (Corresponding author) \\ Department of Medicine, Division of Internal Medicine, \\ Balikesir University School of Medicine, Balikesir, Turkey \\ E-mail: medicus86@hotmail.com \\ Ali Kirik \\ Department of Medicine, Division of Internal Medicine, \\ Dursunbey State Hospital, Balikesir, Turkey \\ E-mail: alikirik87@hotmail.com \\ Omer Toprak \\ Department of Medicine, Division of Nephrology, \\ Balikesir University School of Medicine, Balikesir, Turkey \\ E-mail: omertoprak@balikesir.edu.tr
}

\begin{abstract}
Various indicators are used to evaluate renal function in chronic kidney disease (CKD) patients such as urea, creatinine, serum cystatin C, kidney injury molecule-1, and neutrophil gelatinase-associated lipocalin. However, new clinical parameters are needed to track disease progression. Our goal is to evaluate the relationship between glomerular filtration rate (GFR) and mean platelet volume (MPV) levels in patients with different stages of CKD who are undergoing renal replacement therapy.

Two hundred non-dialysis CKD patients with stage $3(n=84)$, stage $4(n=52)$, and stage $5(n=64)$ were included in the study. They were $18-87$ years old. All of CKD patients including stage 5 have not received renal replacement therapy during two years. MPV levels were determined by used the electrical impedance technology in Application and Research Hospital of University. Systolic and diastolic blood pressure were measured according to Report of Turkish Society of Cardiology-National Guideline for Hypertension Treatment and Follow Up. SPSS for Windows was used for statistical analysis of the data. For stages 3, 4 and 5 in CKD patients, baseline MPV levels were $7.66 \pm 1.04,8.07 \pm 1.16$, and $8.88 \pm 1.05 \mathrm{fL}$, respectively; six-month MPV levels were $8.45 \pm 1.01,8.76 \pm 0.92$, and $9.32 \pm 1.08 \mathrm{fL}$, respectively. The results were statistically significant $(p<0.01)$. There were significant negative correlations between MPV with GFR in all CKD patients ( $r=-0.413$ for baseline, $r=-0.334$ for six-month levels). MPV and GFR levels in patients with atherosclerotic cardiovascular disease (ACVD) and diabetes mellitus (DM) were significantly higher than those without ACVD and DM ( $p<0.05$ for MPV and $p>0.05$ for GFR). Monitoring MPV levels in CKD patients may be a useful indicator for tracking renal function and cardiovascular disease risk.
\end{abstract}

Keywords: Chronic Kidney Disease, Glomerular Filtration Rate, Mean Platelet Volume

DOI: $10.7176 / \mathrm{JSTR} / 5-3-08$

\section{Introduction}

Chronic kidney disease (CKD) is a global epidemiological health problem with increasing incidence and prevalence that result in high costs for health care systems [1]. While cancer, cardiovascular, and cerebrovascular diseases (CVD) are the major causes of mortality, CKD is now presumed to be another leading cause of mortality. $\mathrm{CKD}$ is associated with an age-related decline in renal function accelerated by hypertension, dyslipidemia, diabetes, obesity, or primary renal disorders [2,3]. All phases of CKD are associated with increased risks of cardiovascular morbidity, premature mortality, and decreased quality of human life [4]. The guidelines of the National Kidney Foundation's Kidney Disease Outcomes Quality Initiative (KDOQI) define CKD as sustained renal injury with structural or functional abnormalities (e.g., microalbuminuria / proteinuria, hematuria, histological, or imaging defects), or glomerular filtration rate (GFR) of less than $60 \mathrm{~mL} / \mathrm{min} / 1.73 \mathrm{~m}^{2}$ for at least three months [5]. 
Platelets play an important role in atherosclerotic lesion formation and its complications [6]. Larger platelets have denser granules and are metabolically and enzymatically more active hence their thrombotic potential is higher [7]. Mean Platelet Volume (MPV), which can be easily evaluated with haematological analyzers, is a useful predictive and prognostic biomarker of platelet function and activation can predict athero-thrombotic events such as unstable angina, myocardial infarction, and ischemic stroke [8,9].

Mean platelet volume is part of routine complete blood count (CBC) tests, but it is not often considered carefully by clinicians [10]. MPV has been measured by electrical impedance and optical and optical fluorescence [6]. The electrical impedance method is based on the Coulter principle. It is proportional to the volume of the particle traversing the aperture, so this method can estimate cell sizing and counting [11]. In CKD, decreases in GFR are known to be related to increases in athero-thromboticity. Some studies indicate that MPV levels do not change in dialysis patients; other studies have found negative correlations between GFR and MPV [12, 13].

Although there are various studies on indicators in CKD patients it has been reported in recent years that MPV can also be used as a marker in patients with different stages of CKD. Studies have also published that MPV level may change in both DM and ACKVD. However, there are not enough studies on the relationship between glomerular filtration rate and mean platelet volume levels in CKD patients with stage five who are without renal replacement therapy. In this study we aimed to evaluate the relationship between MPV and GFR indifferent stages of CKD patients.

\section{Methods}

The medical records of the patients $(n=200)$ with different stages of CKD were reviewed retrospectively. Patients had been admitted between 2012 and 2017 to the nephrology clinic of the School of Medicine in University. Age, sex, height, weight, body mass index (BMI), systolic blood pressure (SBP), and diastolic blood pressure (DBP) were recorded from medical charts of CKD patients. The cause of $\mathrm{CKD}$ and medications were documented. Laboratory parameters were evaluated including white blood cell (WBC) count, haemoglobin (HGB) level, platelet (PLT) count, MPV, glucose, creatinine, parathormone (PTH), protein in spot urine, creatinine in spot urine, and urea and uric acid. Systolic and diastolic blood pressure were measured according to Report of Turkish Society of Cardiology-National Guideline for Hypertension Treatment and Follow Up. Patients have not received renal replacement therapy for two years.

GFR levels were obtained from serum creatinine (Scr) concentration and age according to the published equation from the Chronic Kidney Disease Epidemiology Collaboration (CKD-EPI):

$$
\mathrm{GFR}=141 * \min (\mathrm{Scr} / \kappa, 1)^{\alpha} * \max (\mathrm{Scr} / \kappa, 1)^{-1.209} * 0.993^{\text {age }} * 1.018 \text { [if female] } * 1.159 \text { [if black] }
$$

Scr is serum creatinine $(\mathrm{mg} / \mathrm{dL}), \kappa$ is 0.70 for females and 0.90 for males, $\alpha$ is -0.329 for females and -0.411 for males, min indicates the minimum of $\mathrm{Scr} / \kappa$ or 1,0 , and $\max$ indicates the maximum of $\mathrm{Scr} / \kappa$ or 1,0 .

Patients were grouped into stages 3-5 according to GFR values in $\mathrm{mL} / \mathrm{min} / 1.73 \mathrm{~m}^{2}$ : Stage 3 was defined as 59.9930.00 , stage 4 as 29.99-15.00, and stage 5 as $<15.00$. Routine analysis in our hospital is to use tubes with EDTA for complete blood counts and MPV is determined by a Sysmex XE-2100 (Sysmex Corporation, Kobe, Japan) within 1-2 hours after venous puncture. Normal MPV values in our laboratory range between 7 and $11 \mathrm{fL}$. Prior to the study, all protocols were approved by the ethics committee (The Ethical Committee of University School of Medicine, Approval No. 2017/43).

\section{Exclusion criteria}

Patients with acute infections, hemodialysis disorders, or liver cirrhosis were excluded.

\section{Statistical Analysis}

Statistical analyses were conducted using SPSS for Windows 17.0 (Statistical Package For Social Science, SPSS Inc., Chicago, IL, USA). Results are expressed as means \pm standard deviations; categorical data are presented as absolute values and percentages. Comparison of categorical variables between groups was performed with chisquared $\left(X^{2}\right)$ tests. Continuous variables were compared with t-tests. Pearson's correlation analysis was used to assess the association between MPV and GFR. Multiple comparisons were performed using Tukey's honestly significant difference (HSD) test. To control for relevant confounding factors, one-way analysis of variance (ANOVA) was used. Data were evaluated within $95 \%$ confidence intervals and significance levels of $p<0.05$. 


\section{Results}

A total of 200 CKD patients with non-dialysis were included (108 female and 92 male). The mean ages of female and male patients were $64.70 \pm 11.9$ and $65.29 \pm 12.56$, respectively. Of female patients, $38.0 \%(\mathrm{n}=41)$ were diabetic and $90.7 \%(\mathrm{n}=98)$ were hypertensive. Of male patients, $41.3 \%(\mathrm{n}=38)$ were diabetic and $93.5 \%(\mathrm{n}=86)$ were hypertensive.

The demographic and clinical data of all patients were investigated. There was no statistically significant difference between mean body weight, nor systolic or diastolic blood pressure. There were statistically significant differences between age $(p<0.01)$ and pulse $(p<0.05)$. There were other significant differences for the variables ACVD, BPH, chronic pyelonephritis, thyroid disease, and chronic obstructive pulmonary disease.

The comparison of laboratory variables was performed with ANOVA. Significant differences were found for the baseline laboratory variables creatinine, GFR, MPV, PTH, spot urine protein, spot urine creatinine, spot urine protein/creatinine, and urea levels $(p<0.01)$. Creatinine, PTH, spot urine protein, spot urine protein/creatinine, and urea levels were highest in stage 5. The baseline MPV values for stages 3-5 were 7.66 $\pm 1.04,8.07 \pm 1.16$, and $8.88 \pm 1.05 \mathrm{fL}$, respectively (Figure 1). GFR and spot urine creatinine values were highest in stage 3 . The baseline GFR values for stages $3-5$ were $42.43 \pm 7.27,23.76 \pm 3.74$, and $10.73 \pm 2.98$, respectively. There was no statistically significant difference between groups with respect to glucose concentrations, but they were highest in stage 3 . There was no statistically significant difference with respect to WBC, PLT, or uric acid levels, but all three were highest in stage 4 .

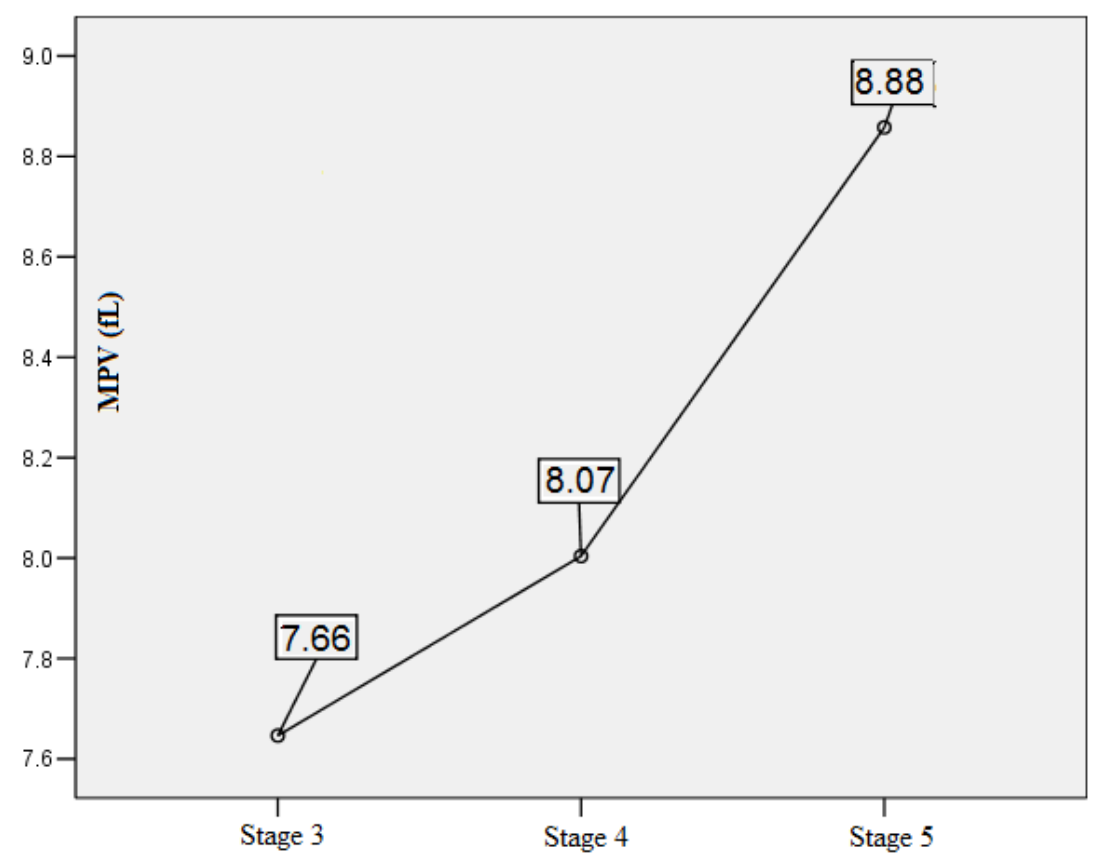

Figure 1. The comparison of baseline MPV values among the different stages of CKD patients.

Statistically significant differences were observed in six-month laboratory variables of all CKD patients for glucose, creatinine, GFR, PTH, spot urine protein, spot urine creatinine, spot urine protein/creatinine, and urea $(p<0.05)$. Creatinine, PTH, spot urine protein, spot urine protein/creatinine, and urea levels were highest in stage 5. Six-month MPV levels were $8.45 \pm 1.01,8.76 \pm 0.92$, and $9.32 \pm 1.08 \mathrm{fL}$ for stages $3-5$, respectively (Figure 2). Glucose, GFR, and spot urine creatinine values were highest in stage 3. Six-month mean GFR levels in stages 35 were $41.77 \pm 7.76,23.50 \pm 4.32$, and $9.20 \pm 3.12$, respectively $(p<0.001)$. There were no statistically significant differences for WBC, PLT, or uric acid levels, but they were highest in stage 4. 


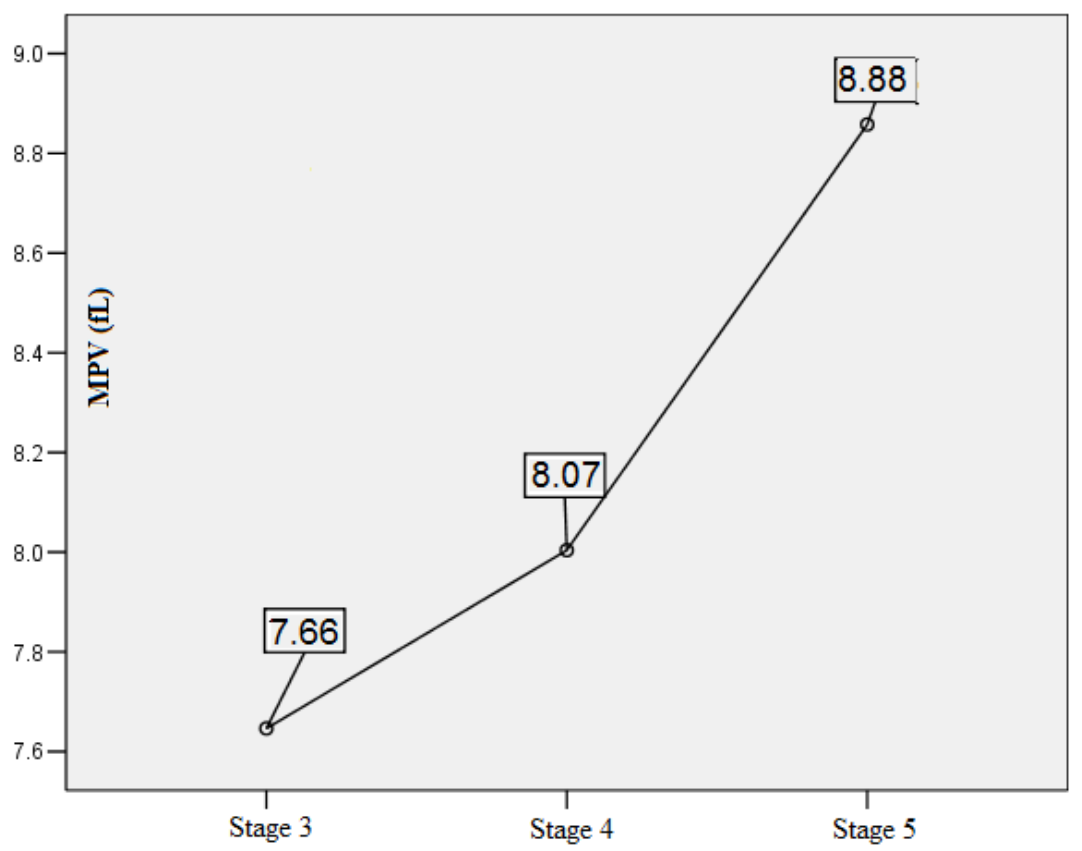

Figure 2. The comparison of MPV levels at after six-month among the different stages of CKD patients.

The comparison of variables at baseline and after six months was performed using t-tests. There were statistically significant differences for MPV levels at all stages. The baseline MPV levels were significantly lower than after six months at all stages. In stage 5, baseline levels of creatinine and urea were significantly lower than six-month levels. Baseline values of GFR and PLT were significantly higher than six-month values.

The relationships between baseline and six-month values were evaluated with Pearson's correlation analysis (Tables 1 and 2). There were strong negative correlations between baseline MPV levels and GFR, HGB, and PLT ( $\mathrm{r}=-0.413,-0.264$, and -0.330 , respectively). MPV was also strongly and positively correlated with creatinine, PTH, spot urine protein, spot urine protein/creatinine, and urea values $(\mathrm{r}=0.396,0.303,0.200,0.233$, and 0.400 , respectively). 
Table 1.The relationships between baseline laboratory parameters of all CKD patients.

\begin{tabular}{|c|c|c|c|c|c|c|c|c|c|c|c|c|}
\hline Parameters & Glucose & Creatinine & GFR & MPV & PTH & $\begin{array}{l}\text { Spot urine } \\
\text { protein }\end{array}$ & $\begin{array}{l}\text { Spot urine } \\
\text { creatinine }\end{array}$ & $\begin{array}{c}\text { Spot urine } \\
\text { protein/creatinine }\end{array}$ & WBC & HGB & PLT & Urea \\
\hline Glucose & 1 & & & & & & & & & & & \\
\hline Creatinine &,- 077 & 1 & & & & & & & & & & \\
\hline GFR & ,087 &,$- 845(* *)$ & 1 & & & & & & & & & \\
\hline MPV & 081 &, $396(* *)$ &,$- 413(* *)$ & 1 & & & & & & & & \\
\hline PTH &, 077 &, $345(* *)$ &,$- 427(* *)$ &, $303(* *)$ & 1 & & & & & & & \\
\hline Spot urine protein &, $215(* *)$ &, $391(* *)$ &,$- 378(* *)$ &, $200(* *)$ &, $177(*)$ & 1 & & & & & & \\
\hline Spot urine creatinine &, 117 &,$- 217(* *)$ &, $312(* *)$ &,- 113 &,$- 207(* *)$ & 025 & 1 & & & & & \\
\hline $\begin{array}{l}\text { Spot urine } \\
\text { protein/creatinine }\end{array}$ &, $146(*)$ &, $453(* *)$ &,$- 473(* *)$ & ,233(**) &, $233(* *)$ &, $845(* *)$ &,$- 289(* *)$ & 1 & & & & \\
\hline WBC & ,098 &,- 035 &,- 020 & ,090 &,- 095 &, $164(*)$ & ,043 & 084 & 1 & & & \\
\hline HGB & 053 &,$- 412(* *)$ &, $494(* *)$ &,$- 264(* *)$ &,$- 210(* *)$ &,- 120 &, $263(* *)$ &,$- 282(* *)$ &, 083 & 1 & & \\
\hline PLT &,- 099 &,- 122 &, 031 &,$- 330(* *)$ &,- 047 & ,106 &,- 040 &, 102 &, $372(* *)$ &,- 106 & 1 & \\
\hline Urea &, 015 &, $855(* *)$ &,$- 776(* *)$ &, $400(* *)$ &, $412(* *)$ &, $340(* *)$ &,$- 232(* *)$ &, $395(* *)$ & 023 &,$- 381(* *)$ &,- 067 & 1 \\
\hline Uric acid & ,074 & 105 &,$- 148(*)$ & ,036 &, $143(*)$ & ,130 & ,052 & ,032 &, $281(* *)$ & ,061 & ,109 &, $210(* *)$ \\
\hline
\end{tabular}

${ }^{*} p<0.05 ;{ }^{* *} p<0.001$ 
Table 2.The relationships between six-month laboratory parameters of all CKD patients.

\begin{tabular}{|c|c|c|c|c|c|c|c|c|c|c|c|c|}
\hline Parameters & Glucose & Creatinine & GFR & MPV & PTH & $\begin{array}{c}\text { Spot urine } \\
\text { protein }\end{array}$ & $\begin{array}{l}\text { Spot urine } \\
\text { creatinine }\end{array}$ & $\begin{array}{l}\text { Spot urine } \\
\text { protein/ } \\
\text { creatinine }\end{array}$ & WBC & HGB & PLT & Urea \\
\hline Glucose & 1 & & & & & & & & & & & \\
\hline Creatinine &,$- 145(*)$ & 1 & & & & & & & & & & \\
\hline GFR & , 108 &,$- 832(* *)$ & 1 & & & & & & & & & \\
\hline MPV &,- 038 &, $327(* *)$ &,$- 334(* *)$ & 1 & & & & & & & & \\
\hline PTH &,- 019 &, $404(* *)$ &,$- 424(* *)$ &, 111 & 1 & & & & & & & \\
\hline Spot urine protein &, 136 &, $297(* *)$ &,$- 312(* *)$ &, $144(*)$ & ,089 & 1 & & & & & & \\
\hline Spot urine creatinine &, 133 &,$- 258(* *)$ &, $265(* *)$ &,- 060 &,$- 153(*)$ &,- 018 & 1 & & & & & \\
\hline $\begin{array}{l}\text { Spot urine } \\
\text { protein/creatinine }\end{array}$ & 049 &, $422(* *)$ &,$- 445(* *)$ &, $163(*)$ &, $143(*)$ &, $850(* *)$ &,$- 293(* *)$ & 1 & & & & \\
\hline WBC &, $190(* *)$ &,- 041 & ,000 &, 121 & 023 &, 127 &,- 010 &, 126 & 1 & & & \\
\hline HGB &, $198(* *)$ &,$- 455(* *)$ &, $525(* *)$ &,$- 162(*)$ &,$- 344(* *)$ &,- 021 &, $266(* *)$ &,$- 165(*)$ &, 110 & 1 & & \\
\hline PLT &,- 083 &,- 106 & ,024 &,$- 304(* *)$ &,- 015 &, 027 &, 022 & ,064 &, $406(* *)$ &,- 095 & 1 & \\
\hline Urea &,- 088 &, $870(* *)$ &,$- 828(* *)$ &, $326(* *)$ &, $465(* *)$ &, $277(* *)$ &,$- 290(* *)$ &, $407(* *)$ &,- 057 &,$- 528(* *)$ &,- 077 & 1 \\
\hline Uric acid & ,034 &, $196(* *)$ &,$- 226(* *)$ &,- 012 & ,132 & ,094 & ,091 & ,037 &, $185(* *)$ &,- 041 &, $147(*)$ &, $200(* *)$ \\
\hline
\end{tabular}


MPV had a significant negative correlation with GFR and PLT ( $r=-0.334$ and -0.304 , respectively) after six months. There was a negative correlation between MPV and HGB $(\mathrm{r}=-0.162, p<0.05)$. MPV was positively correlated with creatinine, spot urine protein, spot urine protein/creatinine, and urea values $(\mathrm{r}=$ $0.327,0.144,0.163$, and 0.326 , respectively).

The baseline and six-month laboratory variables for CKD patients with and without ACVD were compared using an independent t-test. MPV levels were significantly higher in ACVD patients $(p<0.05)$. However, there were no significant differences in creatinine, GFR, and urea levels between patients with and without ACVD ( $p>0.05)$.

Diabetes mellitus is the most common cause of $\operatorname{CKD}(2,3)$. The baseline and six-month laboratory variables were compared for diabetic and non-diabetic CKD patients. There were significant differences in creatinine and urea levels. MPV and GFR were higher in diabetic CKD patients but the difference was not statistically significant.

\section{Discussion}

Chronic renal failure is a prothrombogenic state that is connected to high cardiovascular morbidity and mortality. Currently, cardiovascular disease is the leading cause of mortality among CKD patients [14]. There are few studies that have investigated the relationship between MPV and GFR in the CKD patients with [15-18] and without dialysis [12]. Sevinç et al. [19] reported no significant MPV difference for patients in stages 3-4. Ju et al. showed MPV increased at later stages, leading the authors to claim that MPV could predict disease severity [12]. They reported a negative correlation between MPV and GFR for CKD patients in stages 2-5. In another study, Luca et al. [20] also reported that MPV had a negative correlation ( $\mathrm{r}=-0.103)$ with GFR in CKD patients without renal replacement therapy.

This study has shown that MPV levels increase as CKD progresses from stage 3 to 5 in patients without renal replacement therapy. The baseline mean MPV levels in stages 3-5 were $7.66 \pm 1.04,8.07 \pm 1.16$, and $8.88 \pm 1.05 \mathrm{fL}$, respectively $(p<0.001)$. The six-month mean MPV levels for stages $3-5$ were $8.45 \pm 1.01$, $8.76 \pm 0.92$, and $9.32 \pm 1.08 \mathrm{fL}$, respectively $(p<0.001)$. A significant negative relationship was found between MPV and GFR in both baseline and six-month values $(p<0.001)$. MPV levels increased markedly as GFR levels decreased. Furthermore, MPV had strong negative correlations with HGB and PLT as well as strong positive correlations with creatinine, spot urine protein, spot urine protein/creatinine, and urea. Baseline MPV and PTH levels were significantly and positively correlated $(\mathrm{r}=0.303, p<0.001)$ whereas there was no significant correlation between MPV and PTH after six-months $(\mathrm{r}=0.111, p>0.05)$.

There was a statistically significant difference between baseline and six-month MPV levels at all stages. Six-month MPV values were significantly higher than baseline values at all stages. Baseline values of creatinine and urea at stage 5 were significantly lower than six-month values, while baseline values of GFR and PLT were significantly higher than six-month values.

Acute coronary syndromes (ACS) are a set of signs and symptoms that result from the rupture of a plaque and are a consequence of platelet-rich coronary thrombus formation. MPV, which is widely available in clinical application and research, is a potentially useful biomarker of platelet activity in cardiovascular disease [21, 22]. Sansanayudh et al. reported that MPV was significantly higher in patients with coronary artery disease (CAD) [23]. Ju et al. documented [12] that patients with CAD or cerebrovascular disease (CVD) had higher MPV levels than those without CAD or CVD. Similarly, in this study, MPV was significantly higher in ACVD patients $(p<0.05)$.

Şengül et al. reported [24] MPV was significantly higher in diabetic CKD patients than non-diabetic $(p<0.05)$. In a similar study, Turgutalp et al. documented that MPV levels were higher in all diabetic patients $(p<0.05)$ [25].

Yenigün et al.'s (15) prospective study included 812 CKD patients at stages $1-5$. Mean MPV levels were higher in diabetic $(9.5 \pm 1.3 \mathrm{fL})$ than non-diabetic patients $(9.3 \pm 1.4 \mathrm{fL})(p=0.024)$. There was a positive correlation between MPV and CKD stage. In the present study, MPV and GFR were higher in diabetic than non-diabetic CKD patients, but the difference was not significant $(p>0.05)$. MPV levels in diabetic patients $(\mathrm{n}=79)$ were $8.98 \pm 1.15 \mathrm{fL}$ and $8.66 \pm 1.0 \mathrm{fL}$ in non-diabetic patients $(\mathrm{n}=121)$.

$\mathrm{DM}$ is one of the major causes of CKD in both developed and developing countries [26, 27]. According to the Turkish Society of Nephrology, diabetic patients comprise $37.3 \%$ of the hemodialysis population in Turkey [28]. Şengül et al. reported that urea and serum creatinine levels were lower in diabetic patients than without DM ( $p=0.253$ and $p=0.015)$ [15]. In this study, there were significant differences in creatinine and urea levels between diabetic and non-diabetic CKD patients $(p=0.028)$. The mean urea level in DM patients was $88.68 \pm 48.58 \mathrm{mg} / \mathrm{dL}$ whereas in non-diabetics it was $101.55 \pm 59.30 \mathrm{mg} / \mathrm{dL}$. The mean creatinine level in DM patients was $2.67 \pm 1.80 \mathrm{mg} / \mathrm{dL}$ and in non-diabetics it was $3.45 \pm 2.42 \mathrm{mg} / \mathrm{dL}$

66 | P a g e

www.iiste.org 
$(p=0.002)$. There were some limitations to this study. The timing and methods of blood sample preparation are an important factor in measuring MPV. Because this study was retrospective, it is not clear whether the potential influence of anticoagulants on MPV was fully controlled. Furthermore, some risk factors are known to correlate with MPV such as smoking and inflammation status, which may have affected MPV levels.

\section{Conclusion}

This study provides a significant advantage over the other studies available, such as choice of CKD patients without renal replacement therapy for two years in stage 5 . We detected significant negative correlations between MPV and GFR in CKD patients with non-dialysis. As CKD progressed from stage 3 to 5, MPV increased significantly. Hence MPV maybe a good predictor of the progression of kidney disease. Moreover, MPV levels in CKD patients with ACVD and DM were significantly higher than in patients without ACVD and DM. Therefore, in clinical practices and research, MPV may also be a useful bioindicator of increased risks of ACVD in CKD patients. Larger-scale studies should be done to shed more light on the potential predictive value of MPV as a marker of the progression of kidney disease.

\section{Declaration of interest}

The authors declared no conflicts of interest.

\section{References}

1. Jones CA, McQuillan GM, Kusek JW, Eberhardt MS, Herman WH, Coresh J, et al. Serum creatinine levels in the US population: Third National Health and Nutrition Examination Survey. Am J Kidney Dis 1998; 32: 992-999.

2. Best PJ, Reddan DN, Berger PB, Szczech LA, McCullough PA, Califf RM. Cardiovascular disease and chronic kidney disease: insights and an update. Am Heart J 2004; 148: 230-242.

3. Schlaich MP, Socratous F, Hennebry S, Eikelis N, Lambert EA, Straznicky N, et al. Sympathetic activation in chronic renal failure. J Am Soc Nephrol 2009;20:933-939.

4. Go AS, Chertow GM, Fan D, McCulloch CE, Hsu CY. Chronic kidney disease and the risks of death, cardiovascular events, and hospitalization. The New England J Med 2004; 351(13): 1296305 .

5. National Kidney Foundation. K/DOQI Clinical practice guidelines for chronic kidney disease: Evaluation, classification, and stratification. Am J Kidney Dis 2002; 39: 1-266.

6. Massberg S, Schulz C, Gawaz M. Role of platelets in the pathophysiology of acute coronary syndrome. Semin Vasc Med 2003; 3(2): 147-162.

7. Thombson CB, Eaton K, Princiotta SM, Rushin CA, Valeri CR. Size dependent platelet subpopulations: relationship of platelet volume to ultrastructure, enzymatic activity, and function. Br J Haematol 1982; 50: 509-519.

8. Greisenegger S, Endler G, Hsieh K, Tentschert S, Mannhalter C, Lalouschek W. Is elevated mean platelet volume associated with a worse outcome in patients with acute ischemic cerebrovascular events? Stroke 2004; 35: 1688-1691.

9. Bath P, Algert C, Chapman N, Neal B. Association of mean platelet volume with risk of stroke among 3134 individuals with history of cerebrovascular disease. Stroke 2004; 35: 622-626.

10.Asanuma M, Seino K, Mizuno T, Nasu M, Yamauchi F, Fujishima M. Plasma thrombopoietin level and platelet indices in hemodialysis patients receiving recombinant human erythropoietin. Int J Lab Hematol 2010; 32: 312-319.

11. Michelson AD. Platelets, 3rd edn. Waltham, London, MA: Academic Press; 2013. 
12. Ju HY, Kim JK, Hur SM, Woo SA, Park KA, Park MY, et al. Could mean platelet volume be a promising biomarker of progression of chronic kidney disease? Platelets 2015; 26: 143-147.

13. Sakallı H, Baskın E, Bayrakçı US, Gülleroğlu KS, Moray G, Haberal M. Mean platelet volume as a potential predictor of renovascular thrombosis after renal transplant. Exp Clin Transplant 2011; 11: 27-31.

14. Moody WE, Edwards NC, Chue CD, Ferro CJ, Townend JN. Arterial disease in chronic kidney disease. Heart 2013; 99: 365-372.

15. Yenigun EC, Aypak C, Turgut D, Piskinpasa SV, Cevher KS, Koc E, et al. Is there a relation between mean platelet volume and chronic kidney disease stages in diabetic patients? Int J Clin Exp Med 2016; 9(1): 330-335.

16. Bilen Y, Cankaya E, Keles M, Gulcan E, Uyanik A, Turkeli M, et al. Does decreased mean platelet volume predict inflammation in chronic renal failure, dialysis, and transplanted patients? Ren Fail 2014; 36(1): 69-72.

17. Henning BF, Zidek W, Linder B, Tepel M. Mean platelet volume and coronary heart disease in hemodialysis patients. Kidney Blood Press Res 2002;25:103-108.

18. Altun E, Paydas S, Kaya B, Seydaogulları G. The relationship between inflammation, blood pressure, and mean platelet volume in chronic kidney disease. Saudi J Kidney Dis Transpl 2016; 27(4): 836-838.

19. Yilmaz G, Sevinc C, Ustundag S, Yavuz YC, Hacıbekiroglu T, Hatipoglu E. The relationship between mean platelet volume and neutrophil/ymphocyte ratio with inflammation and proteinuria in chronic kidney disease. Saudi J Kidney Dis Transpl 2017; 28(1): 90-94

20. Verdoia M, Barbieri L, Schaffer A, Bellomo G, Marino P, Luca G De. Impact of renal function on mean platelet volume and its relationship with coronary artery disease: A single-centre cohort study. Thromb Res 2016; 141: 139-144.

21. Davi G, Patrono C. Platelet activation and atherothrombosis. N Engl J Med 2007; 357: 2482-2494.

22. Coppinger JA, Cagney G, Toomey S, Kislinger T, Belton O, McRedmond JP, et al. Characterization of the proteins released from activated platelets leads to localization of novel platelet proteins in human atherosclerotic lesions. Blood 2004; 103: 2096-2104.

23. Sansanayudh N, Anothaisintawee T, Muntham D, McEvoy M, Attia J, Thakkinstian A. Mean platelet volume and coronary artery disease: a systematic review and meta-analysis. Int $\mathrm{J}$ Cardiol 2014; 175(3): 433-40.

24. Şengül E, Öğütcen Z, KılıçHalhallı GS, Sevener D. Mean platelet volume in patients with diabetic and non-diabetic chronic kidney disease. Med J Kocaeli 2013; 3: 14-17.

25. Turgutalp K, Özhan O, Akbay E, Tombak A, Tiftik N, Ozcan T, et al. Mean platelet volume and related factors in patients at different stages of diabetic nephropathy: A Preliminary Study. Clin Appl Thromb Hemost 2014; 20(2): 190-195.

26. McClellan WM, Flanders WD. Risk factors for progressive chronic kidney disease. J Am Soc Nephrol 2003; 14: S65-S70.

27. Bamanikar SA, Bamanikar AA, Arora A. Study of serum urea and creatinine in diabetic and nondiabetic patients in in a tertiary teaching hospital. The J Med Res 2016; 2(1): 12-15.

28. Suleymanlar G, Serdengeçti K, Altıparmak MR, Seyahi N, Jager K, Erek E. Registry of the Nephrology Dialysis and Transplantation in Turkey. Published by the Turkish Society of Nephrology, Istanbul, 2011. 